\title{
Place of panretinal photocoagulation and trabeculectomy in the management of neovascular glaucoma
}

\author{
D. W. FLANAGAN AND R. K. BLACH \\ From Moorfields Eye Hospital, City Road, London ECIV 2PD
}

\begin{abstract}
SUMMARY Established neovascular glaucoma in the presence of clear media can be treated by panphotocoagulation followed by drainage surgery. Three cases are described, and the advantages of this procedure as opposed to others available are discussed. Photocoagulation must be performed early before the development of opaque ocular media obscures the retina.
\end{abstract}

Neovascular glaucoma occurs as a result of retinal ischaemia, most commonly following retinal vein occlusion and proliferative diabetic retinopathy. Initially, new vessels grow in the angle of the anterior chamber. Fibrosis is associated with the neovascularisation, and as the fibrous tissue contracts so the angle becomes closed and neovascular glaucoma ensues.

Neovascularisation can be prevented by panphotocoagulation of the retina and even reversed in the early stages before fibrous tissue develops. ${ }^{1}$ However, once the angle becomes closed with the fibrous tissue, panphotocoagulation will not affect the intraocular pressure. Moreover, classical drainage procedures do not work, since the drainage channel becomes invaded by new blood vessels and blocked by fibrous tissue. As an alternative to drainage procedures, therefore, the insertion of plastic tubes as described by Molteno et al. ${ }^{23}$ or by Krupin et al. ${ }^{4}$ has been advocated. Although these sometimes give rise to successful results, the outcome is unpredictable and often disappointing. ${ }^{5}$

If the neovascular element can be removed and further neovascularisation prevented, then we are left with an uncomplicated angle-closure problem which should be amenable to classical drainage surgery.

We describe 3 cases in which preliminary photocoagulation was undertaken to cause regression of the neovascular element prior to drainage surgeryin our case trabeculectomy.

Correspondence to Mr D. W. Flanagan, FRCS.

\section{Case reports}

CASE 1

A 55-year-old man with a 7-year history of diabetes mellitus was seen in January 1982 complaining of pain and reduced vision in his left eye for 4 months. The pain had started the day before he was seen. The visual acuity was $6 / 6$ in the right eye and $4 / 60$ in the left eye. The left intraocular pressure was grossly elevated to $55 \mathrm{mmHg}$ and there was marked iris rubeosis and corneal oedema. The right intraocular pressure was $18 \mathrm{mmHg}$. Treatment with topical atropine and dexamethasone relieved the pain and reduced the left intraocular pressure to $30 \mathrm{mmHg}$. This allowed the cornea to clear and the fundus to be visualised. There was evidence of a long-standing retinal vein occlusion with forward disc new vessels and gross macular oedema. The anterior chamber angle was open but covered by rubeotic blood vessels.

Fluorescein angiography of the left eye revealed extensive retinal capillary closure as well as forward disc new vessels. The right fundus showed only mild background diabetic retinopathy.

The left retina was then panphotocoagulated, receiving 3680 argon laser burns. Six weeks later the iris rubeosis had disappeared. The anterior chamber angle was occluded by avascular peripheral anterior synechiae. The left intraocular pressure remained at $40 \mathrm{mmHg}$ despite $1 \mathrm{~g}$ acetazolamide (Diamox) daily. A left trabeculectomy was performed. Five months postoperatively the left intraocular pressure remained at $15 \mathrm{mmHg}$ without further treatment and the visual acuity was $6 / 60$. One month postoperatively the 
forward disc new vessels and iris rubeosis recurred; these responded rapidly to further argon laser photocoagulation.

\section{CASE 2}

A 31-year-old woman noted blurred vision in the left eye in June 1981. It was accompanied by slight ocular discomfort, but as the visual disturbance was minimal no action was taken. She attended Moorfields Eye Hospital in January 1982 and was found to have a left intraocular pressure in excess of $50 \mathrm{mmHg}$. There was marked iris rubeosis and closure of the anterior chamber drainage angle by an avascular membrane. Despite this the visual acuity in the left eye remained at $6 / 24$ with a small myopic correction, and $6 / 9$ with a pinhole. The left optic disc was pale with collateral venous shunts. The right eye was normal with a vision of $6 / 6$ with a small myopic correction.

Fluorescein angiography of the left eye revealed extensive peripheral retinal capillary closure and forward disc new vessels. The left neovascular glaucoma was thought to be secondary to a central retinal vein occlusion 6 months previously.

A combination of acetazolomide and timolol reduced the intraocular pressure to $40 \mathrm{mmHg}$. The left retina was then panphotocoagulated, receiving 2492 argon laser burns. One week later the neovascular iris vessels and disc new vessels had regressed significantly, leaving an anterior chamber drainage angle occluded by avascular tissue. Because the intraocular pressure remained at $40 \mathrm{mmHg}$ on acetazolomide and timolol a left trabeculectomy was performed. Five months postoperatively the left intraocular pressure was $17 \mathrm{mmHg}$ without treatment. The left visual acuity is now $6 / 12$ with a $-2 \cdot 50$ correction. There is no evidence of iris or retinal neovascularisation.

\section{CASE 3}

A 26-year-old woman with a 19-year history of diabetes mellitus developed bilateral proliferative retinopathy in December 1979 during her first pregnancy. Her visual acuity was then $6 / 18$ in the right eye and $6 / 9$ in the left eye. The proliferative process progressed despite extensive xenon panphotocoagulation. By April 1980 the right visual acuity was reduced to perception of light and the left to $6 / 60$. There was a total right traction retinal detachment, with iris rubeosis and a retrolental vascular membrane. In the left eye there was a complex traction retinal detachment involving the macula with an early cortical lens opacity. A left lensectomy, vitrectomy, and membranectomy followed by encirclement was performed in May 1980 . This was successful in reattaching the retina. The right eye was considered to be untreatable and no
Table 1 Prophylaxis and treatment of neovascular glaucoma

\begin{tabular}{|c|c|}
\hline Stage & Treatment \\
\hline $\begin{array}{l}\text { 1. Retinal ischaemia } \\
\text { 2. Angle rubeosis } \\
\text { 3. Angle fibrosis and peripheral } \\
\text { anterior synechiae }\end{array}$ & $\begin{array}{l}\text { Panphotocoagulation } \\
\text { Panphotocoagulation } \\
\text { See Table } 2\end{array}$ \\
\hline 4. Absolute glaucoma & Atropine, steroids, cryotherapy \\
\hline
\end{tabular}

action was taken. Unfortunately the eye developed neovascular glaucoma postoperatively. Iris neovascularisation regressed following xenon panphotocoagulation, but the anterior chamber angle remained occluded by avascular tissue. The intraocular pressure rose to $40 \mathrm{mmHg}$ despite acetazolomide and timolol. A left trabeculectomy was performed in July 1981 . One year postoperatively the intraocular pressure was $20 \mathrm{mmHg}$ on timolol $0.5 \%$ b.d. The left visual acuity was $6 / 18$ with an aphakic correction.

All 3 patients now have useful vision. Two of the patients have a normal intraocular pressure without additional treatment; the other requires topical timolol maleate twice daily to maintain normal intraocular pressure.

\section{Discussion}

The management of neovascular glaucoma from the incipient stage to the established condition and of absolute glaucoma is summarised in Table 1. This paper is concerned with the management of stage III, that is to say, a neovascular angle with fibrosis and peripli2ral anterior synechiae. Our particular option, panphotocoagulation followed by drainage surgery, depends on the presence of a clear media and is therefore applicable only to a minority of cases.

The alternatives in the management of stage III thrombotic glaucoma are summarised in Table 2.

1. INSERTION OF AN ARTIFICIAL DRAINAGE TUBE Several types of drainage tube have been described. These do not require clear media. However, they

Table 2 Treatment options for neovascular glaucoma

\begin{tabular}{lll}
\hline Treatment & Advantages & Disadvantages \\
\hline $\begin{array}{l}\text { 1. Artificial drainage } \\
\text { tube }\end{array}$ & $\begin{array}{l}\text { Immediate reduction } \\
\text { in intraocular pressure }\end{array}$ & Unreliable \\
$\begin{array}{l}\text { 2. Retinal cryoablation } \\
\text { Opaque media do not } \\
\text { prevent treatment }\end{array}$ & $\begin{array}{l}\text { Risk of retinal } \\
\text { detachment }\end{array}$ \\
$\begin{array}{l}\text { 3. Cryoablation and } \\
\text { drainage }\end{array}$ & $\begin{array}{l}\text { Opaque media do not } \\
\text { prevent treatment } \\
\text { Sisk of retinal } \\
\text { detachment } \\
\text { 4. Panphotocoagulation } \\
\text { and drainage }\end{array}$ & $\begin{array}{l}\text { Slear media are } \\
\text { essential }\end{array}$ \\
\hline
\end{tabular}


tend to be unreliable in that they get blocked, and may give rise to loss of the anterior chamber, infection, and lens opacities. There are occasions in which they certainly do work. They may well work more efficiently when the lens has been removed.

\section{RETINAL CRYOABLATION}

This has the advantage that it may be used in the presence of opaque media. However, it is more dangerous than panphotocoagulation, since it may give rise to serous detachment of the retina. If retinal fibrous tissue is already present, as, for example, with proliferative retinopathy, the detachment may not settle spontaneously. Nevertheless, it is often the only method of treatment that is available, and it has the advantage that cyclocryotherapy can be performed at the same time. Three rows of cryotherapy are applied to the retina under the conjunctiva in one hemisphere 10,13 , and $16 \mathrm{~mm}$ from the limbus. In the opposite hemisphere cryotherapy is applied $2 \mathrm{~mm}$ from the limbus for $180^{\circ}$, each application being adjacent to the next and applied for one minute by the clock. In our experience this treatment frequently results in a quiet comfortable eye but rarely saves useful vision.

\section{RETINAL CRYOABLATION}

Retinal cryoablation followed by drainage surgery is theoretically possible but we have no experience of it.

\section{PHOTOCOAGULATION FOLLOWED BY DRAINAGE SURGERY}

Three cases are described. These were photocoagulated before irreversible corneal decompensation, cataract, and vitreous haze obscured the fundus. The treatment caused regression of the rubeosis, leaving an anterior chamber drainage angle closed by avascular tissue. Thus trabeculectomy could be performed without risk of haemorrhage or closure of the fistula by neovascular tissue.

The recurrence of iris rubeosis and proliferative retinopathy in case 2 emphasises the need for careful follow-up.

Therefore we consider that neovascular glaucoma need not always result in painful blindness. In certain cases a combination of early panphotocoagulation and later drainage surgery can preserve vision and control intraocular pressure.

\section{References}

1 Blach RK, Hitchings RA, Laatikainen L. Thrombotic glaucoma prophylaxis and management. Trans Ophthalmol Soc UK 1977; 97: 275-9.

2 Molteno ACB, Ancker E, Bartholomew RS. Drainage operations for neovascular glaucoma. Trans Ophthalmol Soc NZ 1980; 32: 101-5.

3 Anker E, Molteno ACB. Molteno drainage implant for neovascular glaucoma. Trans Ophthalmol Soc UK 1982; 102: 122-3.

4 Krupin T, Podos SM, Becker B, Newdirk JB. Valve implants in filtering surgery. Am J Ophthalmol 1976; 81: 232-5.

5 Sutton GE, Popp JC, Records RE. Krupin-Denver valve for neovascular glaucoma. Trans Ophthalmol Soc UK 1982; 102: 119-21. 